\title{
Shape recovery in high temperature shape memory alloys based on the Ru-Nb and Ru-Ta systems
}

\author{
A. Manzoni ${ }^{1 *}$, K. Chastaing ${ }^{1}$, A. Denquin ${ }^{1}$, P. Vermaut ${ }^{2}$, R. Portier $^{2}$ \\ ${ }^{1}$ ONERA, 29 Avenue de la Division Leclerc, Châtillon, 92260, France \\ ${ }^{2}$ GMS-LPCS UMR CNRS 7045 ChimieParisTech, 11 rue Pierre et Marie Curie, 75231 Paris Cedex 05, France
}

\begin{abstract}
This work investigates the high-temperature behaviour of three RuTa alloys and three RuNb alloys. The first step was to determine how $\mathrm{Ta}$ or $\mathrm{Nb}$ content affects the MT temperatures. The monoclinic $\mathrm{Ru}_{50} \mathrm{Ta}_{50}$ and $\mathrm{Ru}_{50} \mathrm{Nb}_{50}$ alloys undergo two successive displacive transformations from the high temperature $\beta$ phase field: $\beta$ (B2) $\rightarrow \beta^{\prime}$ (tetragonal) $\rightarrow \beta^{\prime \prime}$ (monoclinic) whereas $\mathrm{Ru}_{45} \mathrm{Nb}_{55}, \mathrm{Ru}_{45} \mathrm{Ta}_{55}, \mathrm{Ru}_{43} \mathrm{Nb}_{57}$, and $\mathrm{Ru}_{43} \mathrm{Ta}_{57}$ exhibit a single transition from cubic to tetragonal on cooling. All alloys exhibit a highly twinned microstructure with a (011) compound twinning mode. The main feature of the $\beta^{\prime} \rightarrow \beta^{\prime}$ ' transformation is the formation of domains boundaries separating translation variants instead of formation of new twin separating orientation variants.

The shape memory effect was studied through compression tests performed in the $\beta$ ' or $\beta$ " phase. The total shape recovery is mainly due to the $\beta^{\prime} \rightarrow \beta$ transformation and appears to decrease from about $3 \%$ for the monoclinic alloys to about $0.1 \%$ for alloys with $43 \% \mathrm{Ru}$ in accordance with the evolution of the lattice parameters of martensites.
\end{abstract}

\section{Introduction}

Shape memory alloys (SMAs) have the ability to perform both sensing and actuating functions and have consequently been identified as potential materials for various functions within turbo-engines components. The introduction of this category of materials in aerospace gas turbines however requires SMAs with martensitic transformation (MT) temperature above $250^{\circ} \mathrm{C}$, which is well over MT temperatures of commercially available materials. Among the different SMAs, only a few can be used as high temperature SMAs, i.e. Ti-Ni(Pt,Pd), $\mathrm{NiAl}, \mathrm{RuTa}$ and RuNb alloys [1]. Ti-Ni(Pd-Pt) systems demonstrate high MT temperature but are reported to present a poor shape memory effect (SME) at high temperature, which may be due to a decrease of the critical stress for slip towards a level that is characteristic for the martensite detwinning process [2]. NiAl alloys transformation temperatures may be raised up to $900^{\circ} \mathrm{C}$ depending on the composition but the brittle room temperature martensite is not an equilibrium phase and decomposes into $\mathrm{NiAl}+\mathrm{Ni}_{5} \mathrm{Al}_{3}$ upon aging [3]. Equiatomic RuTa and RuNb alloys demonstrate both MT temperatures above $800{ }^{\circ} \mathrm{C}$ and SME [4-6], which makes them a very promising option. These alloys undergo two successive displacive equilibrium transformations [7]. The high-temperature transition takes place on cooling from the cubic B2 $\beta$-phase to a tetragonal $\beta$ '-phase. The second transformation gives rise to a monoclinic $\beta$ ' phase. MT temperatures decrease with increasing $\mathrm{Nb}$ or Ta content. Alloys with a $\mathrm{Nb}$ or Ta content higher than approximately 54 at.\% undergo a single cubic $\rightarrow$ tetragonal transformation $[4,8]$. Shape memory behaviour in these systems has been observed either from the $\beta$ ' or $\beta$ ' ' phase, whereas only the high temperature MT is considered to be responsible for the SME $[9,10]$. This study aims at a better knowledge of the application potential of RuNb and RuTa-based alloys, through: (1) exploring the effect of $\mathrm{Nb}$ or Ta content on the shape recovery, (2) clarifying the effect of each transformation on the shape memory behaviour, (3) establishing the relationship between the microstructural features and the shape memory behaviour. For this purpose, six compositions belonging to the RuNb and RuTa systems, which show martensitic transformation temperatures above $450^{\circ} \mathrm{C}$, were chosen: (1) the $\mathrm{Ru}_{50} \mathrm{Nb}_{50}$ and $\mathrm{Ru}_{50} \mathrm{Ta}_{50}$ alloys, which undergo two successive displacive transformations from the high temperature $\beta$ phase field: $\beta$ (B2) $\rightarrow \beta^{\prime}$ (tetragonal) $\rightarrow \beta^{\prime}$ ' (monoclinic), (2) $\mathrm{Ru}_{45} \mathrm{Nb}_{55}, \mathrm{Ru}_{45} \mathrm{Ta}_{55}, \mathrm{Ru}_{43} \mathrm{Nb}_{57}$, and $\mathrm{Ru}_{43} \mathrm{Ta}_{57}$, which show only the first $\beta \rightarrow \beta$ ' transformation.

\section{Experimental procedures}

The alloys were prepared from elements of commercial purity using the vacuum arc melting technique. All alloys were re-melted several times to ensure homogeneity. Final compositions were determined by atomic absorption spectrometry within an experimental precision of 0.5 at. $\%$ and proved to be very close to the intended compositions (table 1).

Ingots have been homogenised in a vacuum furnace at $1600{ }^{\circ} \mathrm{C}$ for $168 \mathrm{~h}$. All specimens were cut by an electrodischarge machine.

"email: amanzoni@onera.fr

This is an Open Access article distributed under the terms of the Creative Commons Attribution-Noncommercial License (http://creativecommons.org/licenses/by-nc/3.0/), which permits unrestricted use, distribution, and reproduction in any noncommercial medium, provided the original work is properly cited. 
Microstructural observations were performed by scanning electron microscopy (SEM) using a Zeiss DSM962 system operating at $15 \mathrm{kV}$ and transmission electron microscopy (TEM) on a Philips CM20 microscope operating at $200 \mathrm{kV}$. Thin foils for TEM were prepared using a twin-jet electropolishing technique in a polishin g solution based on $\mathrm{H}_{2} \mathrm{SO}_{4}$ and methanol solution at $-20^{\circ} \mathrm{C}$. Transformation temperatures have been determined on homogenised specimens by differential scanning calorimetry (DSC) from RT to $700^{\circ} \mathrm{C}$ on a Mettler Toledo DSC $822 \mathrm{e}$ and from RT to $1200^{\circ} \mathrm{C}$ on a Netzsch DSC404 apparatus with a heating/cooling rate of $10 \mathrm{~K} / \mathrm{min}$. Compression tests curves were carried out in a vacuum furnace at a strain rate of $10^{-4} \mathrm{~s}^{-1}$ on $3 \times 3 \times 6 \mathrm{~mm}^{3} \mathrm{samples}$. Reheating of the deformed samples was performed in the furnace used for compression.

\begin{tabular}{|c|c|c|}
\hline & at. $\% \mathbf{R u}$ & at. $\mathbf{\%} \mathbf{N b}$ or $\mathbf{~} \mathbf{a}$ \\
\hline $\mathbf{R u}_{\mathbf{5 0}} \mathbf{N b}_{\mathbf{5 0}}$ & 49.8 & 50.2 \\
\hline $\mathbf{R u}_{\mathbf{5 0}} \mathbf{T a}_{\mathbf{5 0}}$ & 49.6 & 50.4 \\
\hline $\mathbf{R} \mathbf{u}_{\mathbf{4 5}} \mathbf{N b}_{\mathbf{5 5}}$ & 44.7 & 55.3 \\
\hline $\mathbf{R u}_{\mathbf{4 5}} \mathbf{T a}_{\mathbf{5 5}}$ & 44.6 & 55.4 \\
\hline $\mathbf{R u}_{\mathbf{4 3}} \mathbf{N b}_{\mathbf{5 7}}$ & 42.6 & 57.4 \\
\hline $\mathbf{R u}_{\mathbf{4 3}} \mathbf{T a}_{\mathbf{5 7}}$ & 42.9 & 57.1 \\
\hline
\end{tabular}

Table 1. Experimentally determined compositions of the studied alloys (at.\%)

\section{Results and discussion}

\subsection{Lattice parameters}

The crystallographic structure of both alloys at room temperature was determined from X-ray diffraction experiments and from TEM analysis. As expected from literature, $\mathrm{Ru}_{50} \mathrm{Nb}_{50}$ and $\mathrm{Ru}_{50} \mathrm{Ta}_{50}$ exhibit a monoclinic structure $(\mathrm{P} 2 / \mathrm{m})$, whereas $\mathrm{Ru}_{45} \mathrm{Nb}_{55}, \mathrm{Ru}_{45} \mathrm{Ta}_{55}, \mathrm{Ru}_{43} \mathrm{Nb}_{57}$ and $\mathrm{Ru}_{43} \mathrm{Nb}_{57}$ prove to be tetragonal (P4/mmm). Lattice parameters are reported in table 2 .

\begin{tabular}{|l|c|c|c|c|}
\hline & $\mathbf{a}(\AA)$ & $\mathbf{b}(\AA)$ & $\mathbf{c}(\AA)$ & $\left.\boldsymbol{\beta} \mathbf{(}^{\circ}\right)$ \\
\hline $\mathbf{R} \mathbf{u}_{\mathbf{5 0}} \mathbf{N b}_{\mathbf{5 0}}$ & 8.10 & 4.23 & 5.22 & 97 \\
\hline $\mathbf{R u}_{\mathbf{5 0}} \mathbf{T a}_{\mathbf{5 0}}$ & 7.98 & 4.37 & 5.26 & 97 \\
\hline $\mathbf{R u}_{\mathbf{4 5}} \mathbf{N b}_{\mathbf{5 5}}$ & 3.11 & 3.11 & 3.29 & 90 \\
\hline $\mathbf{R} \mathbf{u}_{\mathbf{4 5}} \mathbf{T a}_{\mathbf{5 5}}$ & 3.09 & 3.09 & 3.31 & 90 \\
\hline $\mathbf{R} \mathbf{u}_{\mathbf{4 3}} \mathbf{N b}_{\mathbf{5 7}}$ & 3.13 & 3.13 & 3.26 & 90 \\
\hline $\mathbf{R} \mathbf{u}_{\mathbf{4 3}} \mathbf{T a}_{\mathbf{5 7}}$ & 3.12 & 3.12 & 3.27 & 90 \\
\hline
\end{tabular}

Table 2. Lattice parameters determined from X-ray and TEM diffraction experiments

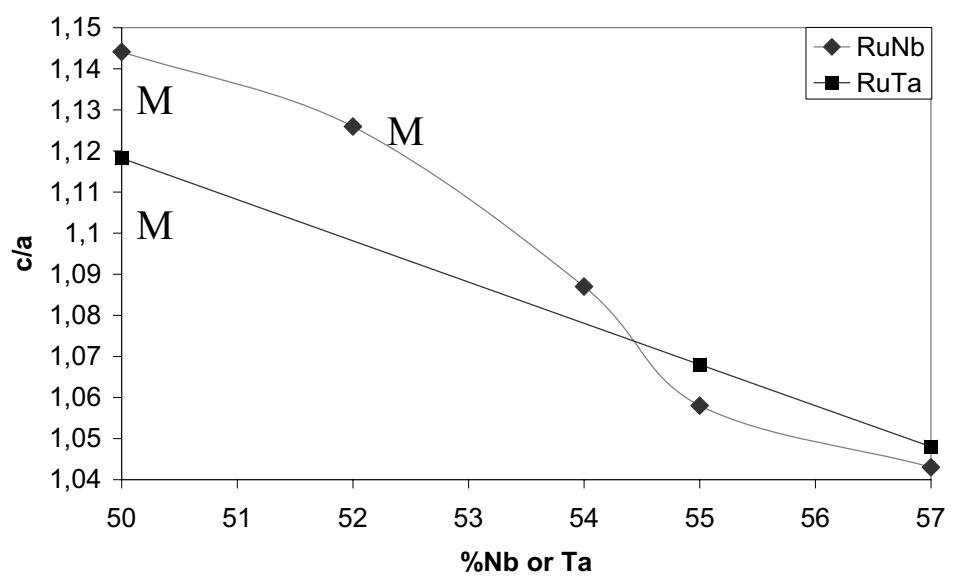

Fig. 1. Comparison between the c/a in the tetragonal alloys and its equivalent for the monoclinic alloys. The c/a has also been calculated for two additional alloys [8,12], $\mathrm{Ru}_{46} \mathrm{Nb}_{54}$ and $\mathrm{Ru}_{48} \mathrm{Nb}_{52}$, not presented any further here.

It can be interesting to consider the evolution of the c/a ratio of the tetragonal unit cell with the composition. The monoclinic alloys having a different unit cell, their c/a cannot be directly compared to the others. However, as a 
first approximation, parameters of the corresponding tetragonal cell have been determined from the monoclinic cell. A theoretical ratio between interplanar distances can be calculated by using the correspondence between the monoclinic and the tetragonal structures $[11,12]$ as follows: $\mathrm{c}_{\mathrm{T}} / \mathrm{a}_{\mathrm{T}}=\mathrm{d}_{001 \mathrm{~T}} / \mathrm{d}_{100 \mathrm{~T}} \rightarrow \mathrm{d}_{20-1 \mathrm{M}} / \mathrm{d}_{1-11 \mathrm{M}}$.

The evolution of the $\mathrm{c} / \mathrm{a}$ ratio of both $\mathrm{RuNb}$ and $\mathrm{RuTa}$ systems is reported in figure 1 . This figure shows that the c/a ratio tends to $1: 1$ with decreasing $\mathrm{Ru}$ content. Above $55 \mathrm{at} \%$ of $\mathrm{Ru}$, the $\mathrm{c} / \mathrm{a}$ ratio of $\mathrm{RuNb}$ alloys is higher than for RuTa alloys.

\subsection{Martensitic transformation}

According to the $\mathrm{x}$-ray results, $\mathrm{Ru}_{45} \mathrm{Nb}_{55}, \mathrm{Ru}_{45} \mathrm{Ta}_{55}, \mathrm{Ru}_{43} \mathrm{Nb}_{57}$ and $\mathrm{Ru}_{43} \mathrm{Nb}_{57}$ are expected to undergo a single cubic-to-tetragonal martensitic transformation whereas a second transformation from this $\beta$ '-tetragonal structure to the $\beta$ "'-monoclinic phase occurs in $\mathrm{Ru}_{50} \mathrm{Nb}_{50}$ and in $\mathrm{Ru}_{50} \mathrm{Ta}_{50}$. DSC measurements (fig. 2) confirm these assumptions.

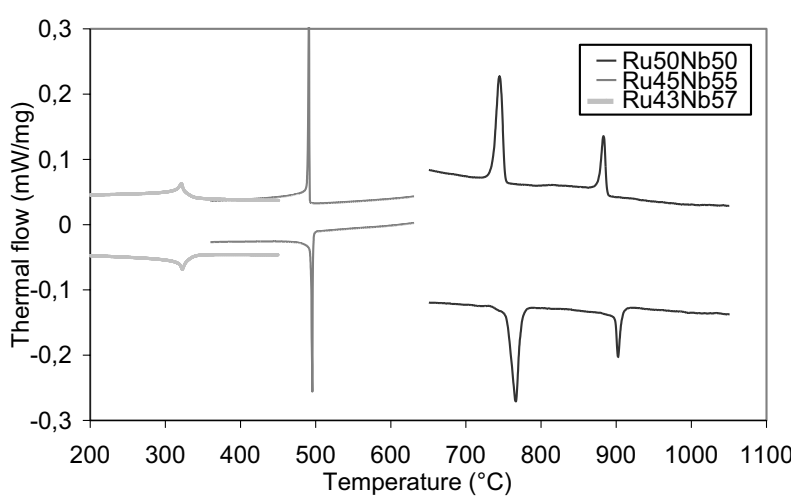

a)

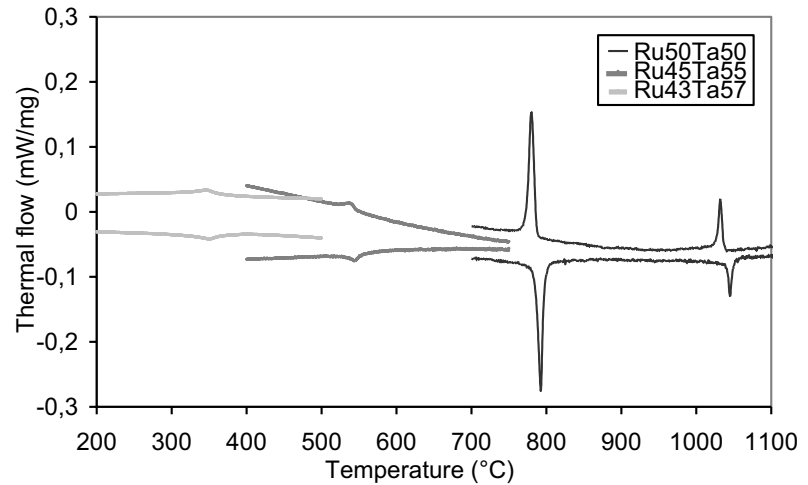

b)

Fig. 2. DSC curves obtained for (a) alloys of the RuNb system, (b) alloys of the RuTa system

The two peaks in the monoclinic alloys can be seen very clearly, as they are well pronounced. This is also true for the single peak in $\mathrm{Ru}_{45} \mathrm{Nb}_{55}$. However, the peaks in $\mathrm{Ru}_{45} \mathrm{Ta}_{55}, \mathrm{Ru}_{43} \mathrm{Nb}_{57}$ and $\mathrm{Ru}_{43} \mathrm{Ta}_{57}$ are very small and rather widely spread. One explanation may be that the energy associated to the transformation decreases with the $\mathrm{Ru}$-content.

It is interesting to note the difference between both systems for 55 at.\% of Ru: the transformation in the $\mathrm{Ru}_{45} \mathrm{Nb}_{55}$ alloy seems to be more instantaneous and pronounced than in the $\mathrm{Ru}_{45} \mathrm{Ta}_{55}$ alloy.

DSC experiments allow the determination of transformation temperatures, which are reported in table 3. MT temperatures decrease with increasing $\mathrm{Nb}$ or Ta content, but remain rather high. One can notice the low hysteresis associated to both transformations.

\begin{tabular}{|c|c|c|c|c|c|c|c|}
\hline \multicolumn{8}{|c|}{ High temperature transformation $\beta \rightarrow \beta$, } \\
\hline & Ms' & Мp' & Mf' & As' & Ap' & Af' & Hyst \\
\hline $\mathbf{R u}_{50} \mathrm{Ta}_{50}$ & 1038 & 1033 & 1028 & 1041 & 1045 & 1050 & 12 \\
\hline $\mathrm{Ru}_{\mathbf{5 0}} \mathrm{Nb}_{\mathbf{5 0}}$ & 887 & 886 & 884 & 898 & 899 & 900 & 13 \\
\hline $\mathrm{Ru}_{45} \mathrm{Ta}_{55}$ & 548 & 538 & 520 & 529 & 543 & 554 & 7 \\
\hline $\mathrm{Ru}_{45} \mathrm{Nb}_{55}$ & 492 & 491 & 489 & 493 & 496 & 496 & 4 \\
\hline $\mathbf{R u}_{\mathbf{4 3}} \mathrm{Ta}_{\mathbf{5 7}}$ & 366 & 347 & 302 & 308 & 350 & 369 & 3 \\
\hline $\mathrm{Ru}_{43} \mathbf{N b}_{57}$ & 327 & 321 & 314 & 318 & 322 & 330 & 3 \\
\hline \multicolumn{8}{|c|}{ Low temperature transformation $\beta^{\prime} \rightarrow \beta^{\prime \prime}$} \\
\hline & Ms" & Mp"' & Mf' & As"' & Ap" & Af'” & Hyst \\
\hline $\mathbf{R u}_{\mathbf{5 0}} \mathbf{T a}_{\mathbf{5 0}}$ & 787 & 780 & 771 & 781 & 793 & 799 & 12 \\
\hline $\mathbf{R u}_{50} \mathbf{N b}_{50}$ & 751 & 746 & 742 & 751 & 760 & 762 & 11 \\
\hline
\end{tabular}

Table 3. Transformation temperatures $\left({ }^{\circ} \mathrm{C}\right)$ and corresponding hysteresis determined from DSC experiments

\subsection{Microstructure}

Microstructural characteristics and their evolution with composition are very similar for RuNb and RuTa systems. All the studied alloys are characterized by a microstructure consisting of lamellar grains with an average diameter of 300 microns (figure $3 \mathrm{a}$ to $3 \mathrm{c}$ ). The lamellae (average width of 10 microns) also exhibit an internal twinning, particularly pronounced in the case of equiatomic composition and sometimes absent in the 
alloys with 45 and $43 \mathrm{at} \%$ of $\mathrm{Ru}$. TEM observations reveal the presence of microtwins, with an average width of 50-100 nm.

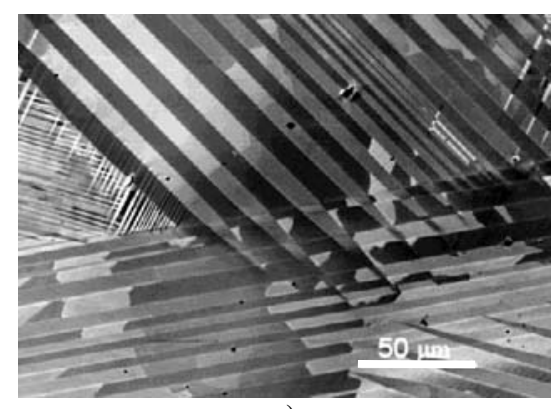

a)

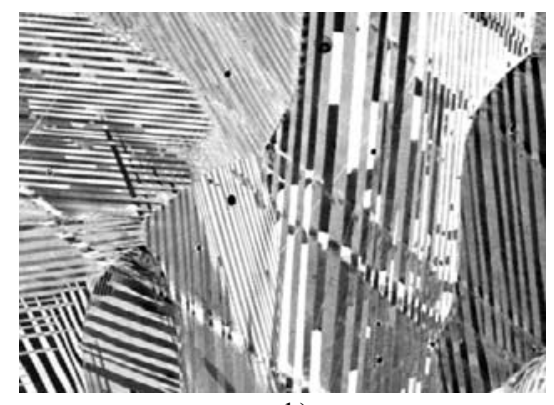

b)

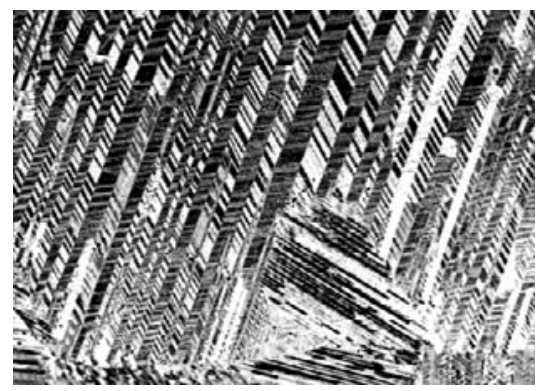

c)

Fig. 3. SEM observations of RuTa alloys, (a) $\mathrm{Ru}_{43} \mathrm{Ta}_{57}$, (b) $\mathrm{Ru}_{45} \mathrm{Ta}_{55}$, (c) $\mathrm{Ru}_{50} \mathrm{Ta}_{50}$.

The twinning mode of the tetragonal martensite is presented in figure 4 . The indexation of the diffraction pattern is consistent with a $(011)_{\mathrm{T}}$ compound twinning mode which correspond to the lattice invariant shear of martensitic cubic $\rightarrow$ tetragonal transformation. It should be noticed that some area are free of microtwins in tetragonal alloys.

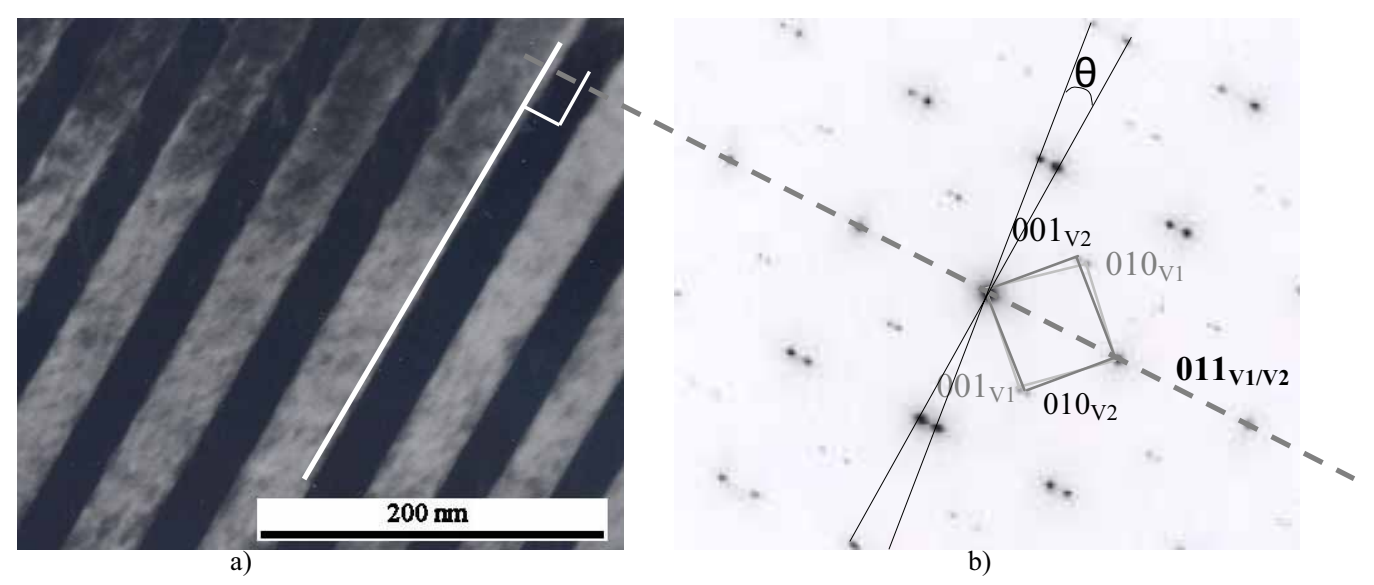

Fig. 4: a) TEM bright field image of fine twins in $\mathrm{Ru}_{45} \mathrm{Nb}_{55}$ alloy, b) corresponding diffraction pattern, the electron beam being parallel to the $[100]_{\mathrm{T}}$ zone axis. The twinning mode is $(011)$ compound.

The twining mode of the monoclinic martensite has been investigated as shown in figure 5 . The indexation of the diffraction pattern shows that the twining plane is $(310)_{\mathrm{M}}$. From the correspondence between the tetragonal and monoclinic unit cells, it has been found that this $(310)_{\mathrm{M}}$ plane corresponds to the $(101)_{\mathrm{T}}$ plane of the tetragonal structure, which is the twining plane of the tetragonal martensite.

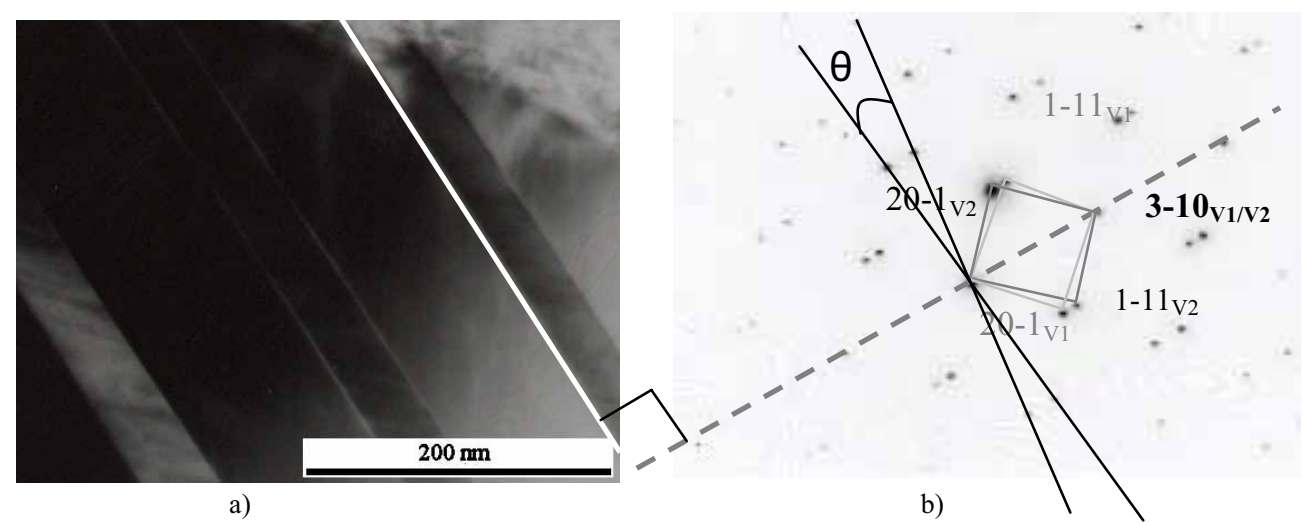

Fig. 5. a) TEM bright field image of fine twins in $\mathrm{Ru}_{50} \mathrm{Ta}_{50}$ alloy, b) corresponding Selected Area Diffraction Pattern indexed using the monoclinic structure of the $\beta$ "' martensite.

This result leads to the conclusion that the second martensitic transformation does not introduce a new twinning mode. Therefore, new twins which may result from the $\beta^{\prime} \rightarrow \beta^{\prime}$ ' transformation are of the same type as those of 
the $\beta \rightarrow \beta$ ' transformation and cannot be distinguished. One single tetragonal orientation variant can transform into one single monoclinic orientation variant, without necessarily introducing new twins [11, 12].

On a smaller scale, bright field images of monoclinic martensite sometimes reveal the presence of wavy domain boundaries inside the microtwins (fig. 6). They can be found in both $\mathrm{Ru}_{50} \mathrm{Nb}_{50}$ and $\mathrm{Ru}_{50} \mathrm{Ta}_{50}$. According to Fonda et al. $[5,13]$ and Chastaing et al. $[11,12]$, these domains are related to the $\beta^{\prime} \rightarrow \beta^{\prime}$ ' transformation.

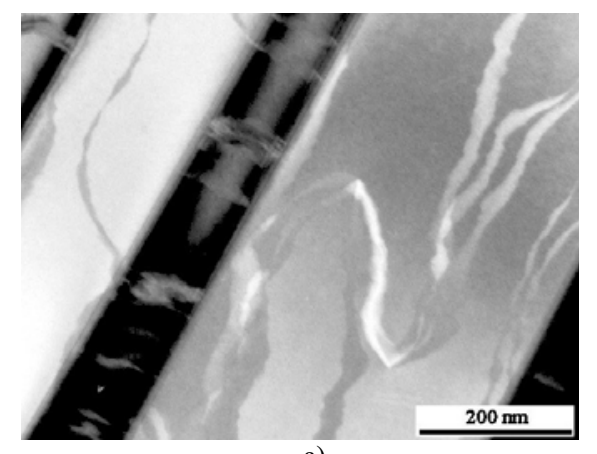

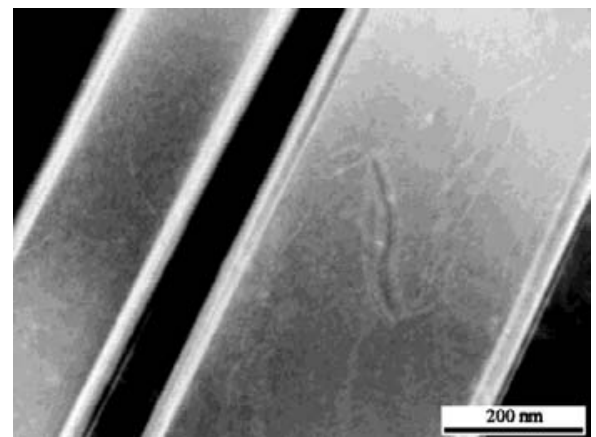

b)

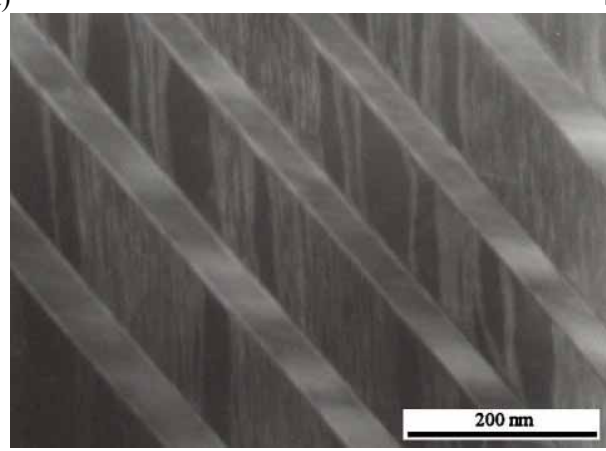

c)

Fig. 6. a) Bright field image of a twinning zone in the $\mathrm{Ru}_{50} \mathrm{Nb}_{50}$ alloy, b) dark field image using the $020_{\mathrm{M}}$ reflection, which is common to both structures. The translation boundaries are then out of contrast, (c) Bright field image of the twinning zone of the $\mathrm{Ru}_{50} \mathrm{Ta}_{50}$ alloy

The number of martensite variants can be obtained from the crystallography. The common subgroup between the two point groups of the monoclinic $(2 / \mathrm{m})$ and tetragonal $(4 / \mathrm{mmm})$ structures is $2 / \mathrm{m}$. The ratio between the order of the mother phase (16) and the common subgroup (4) gives the number of orientation variants. In the present case, the $\beta$ ' $\rightarrow \beta^{\prime}$ ' transformation should introduce 4 orientation variants in addition to the three ones produced by the cubic-tetragonal martensitic transformation. 12 orientation variants are expected in the microstructure of the monoclinic martensite. However, an examination of the unit cells of both phases shows that the monoclinic cell is 6 times bigger than that of the tetragonal cell. This means that some translations of the tetragonal lattice are not entire translations of the monoclinic cell. Since the ratio between the unit cells is 6 , six translation variants are expected separated by 5 translations vectors. These translations have been identified and are listed in table 4 in both frames.

\begin{tabular}{|c|c|}
\hline $\begin{array}{c}\text { Translation expressed in } \\
\text { the } \beta \text { ' frame }\end{array}$ & $\begin{array}{l}\text { Translation expressed } \\
\text { in the } \beta \text { " frame }\end{array}$ \\
\hline $1-11$ & $1 / 3\left[\begin{array}{lll}2 & 0 & 1\end{array}\right]$ \\
\hline $1-10$ & $1 / 3\left[\begin{array}{lll}1 & 0 & 2\end{array}\right]$ \\
\hline $0-10$ & $1 / 6\left[\begin{array}{lll}1 & 3 & 2\end{array}\right]$ \\
\hline $1-21$ & $1 / 6\left[\begin{array}{llll}5 & 3 & 4\end{array}\right]$ \\
\hline $0-11$ & $1 / 2\left[\begin{array}{lll}1 & 1 & 0\end{array}\right]$ \\
\hline
\end{tabular}

Table 4. Translation vectors separating translation variants in the monoclinic martensite

When imaged in dark field and using reflections common to both twins (figure 6b), those defects are extinguished in the $\mathrm{Ru}_{50} \mathrm{Nb}_{50}$ alloy. This is consistent with the results of table 4. However, because of the high density of these defects, this analysis cannot be carried out further by conventional TEM. A quantitative analysis, not presented here, of high resolution TEM images of the boundaries observed in the $\mathrm{Ru}_{50} \mathrm{Nb}_{50}$ using the geometrical phase image analysis technique has been carried out in order to identify the translation vector associated to these planar defects $[11,12]$. A good match has been obtained $[11,12]$ for one boundary with $1 / 6[1$ 32 ] and work is in progress to characterise other boundaries with other translations, as is the case for identifying these defects in the $\mathrm{Ru}_{50} \mathrm{Ta}_{50}$ alloy. 
The major microstructural feature related to the $\beta^{\prime} \rightarrow \beta^{\prime \prime}$ transformation is therefore the formation of wavy boundaries separating translation variants instead of twinning between orientation variants.

\subsection{The shape memory effect}

The influence of $\mathrm{Nb}$ or Ta content on shape recovery was investigated in a first step for the $\beta$ ' $\beta$ transformation. In order to quantify the SME for each alloy, compression tests were performed at $55^{\circ} \mathrm{C}$ below $\mathrm{M}_{\mathrm{p}}$ ' and stopped at various total strains. The length of the specimen was measured at room temperature before testing $\left(L_{0}\right)$ and after compression $(L)$. The remaining length $\left(L_{T T}\right)$ was measured at room temperature after heating up the specimen to $\mathrm{A}_{\mathrm{p}}{ }^{\prime}+150^{\circ} \mathrm{C}$ in the $\mathrm{B} 2$ phase. Compression $(\varepsilon)$ and recovered $\left(\varepsilon_{\mathrm{rec}}\right)$ strains were determined using the following expressions:

$$
\begin{gathered}
\varepsilon=\frac{L_{0}-L}{L_{0}} \\
\varepsilon_{\text {rec }}=\frac{L_{T T}-L}{L_{0}}
\end{gathered}
$$

The evolution of recovered strains with compression strain is reported in figure 7.

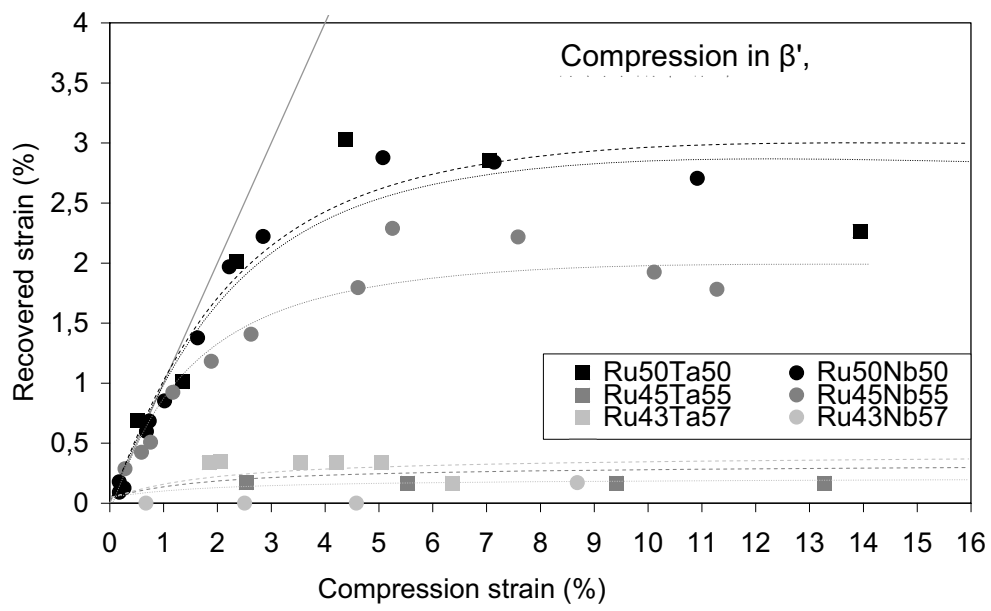

Fig. 7. Recovered strains $\left(\varepsilon_{\text {rec }}\right)$ as a function of compression strain for the six alloys deformed $55^{\circ} \mathrm{C}$ below $\mathrm{M}_{\mathrm{p}}$ '.

All alloys present a shape memory effect associated to the $\beta \rightarrow \beta$ ' transformation. For $\mathrm{Ru}_{50} \mathrm{Nb}_{50}$ and the $\mathrm{Ru}_{50} \mathrm{Ta}_{50}$, $100 \%$ of recovery can be obtained up to about $2 \%$ of preset strain. For compression strain above $4 \%$, the residual strain increases and the maximum recoverable strain reaches a maximum value of $2.8 \%$ for $\mathrm{Ru}_{50} \mathrm{Nb}_{50}$ and $3 \%$ for $\mathrm{Ru}_{50} \mathrm{Ta}_{50}$. A similar behaviour is observed for the $\mathrm{Ru}_{45} \mathrm{Nb}_{55}$ alloy, although the strain for full recovery is $0.5 \%$ and the maximum recoverable strain is $2 \% . \mathrm{Ru}_{45} \mathrm{Ta}_{55}, \mathrm{Ru}_{43} \mathrm{Nb}_{57}$ and $\mathrm{Ru}_{43} \mathrm{Ta}_{57}$ do not show a remarkable shape recovery, the maximum recoverable strain is about $0.1-0.3 \%$ for the three alloys.

For both systems, the shape recovery is highest for equiatomic compositions and decreases with Ru content. As the twinning mode of these alloys is $(011)_{\mathrm{T}}$ compound, the amplitude $\mathrm{s}$ of the twinning shear can be calculated by a simple geometrical consideration from the c/a ratio. The amplitude $\mathrm{s}$ is directly related to the angle $\theta$ between (0-11) of both variants, the twinning plane being (011). This angle can also be measured directly in the diffraction patterns between the two reciprocal vectors $[01-1]^{*}{ }_{\mathrm{v} 1}$ and $[0-11]^{*}{ }_{\mathrm{v} 2}$ (see figures $4 \mathrm{~b}$ and $5 \mathrm{~b}$ ).

$$
\begin{gathered}
s=2 \tan \left(\frac{\theta}{2}\right) \\
\theta=180^{\circ}-4 \arctan \left(\frac{a}{c}\right)
\end{gathered}
$$

The theoretically and experimentally determined twinning shears are regrouped in table 5 . The decrease of shape recovery is probably partly related to the decrease of twinning shear with Ru content.

It is interesting to note that decreasing the temperature for compression should favour the mobility of martensite variant interfaces against plastic deformation. As a counterpart, the $45 \%$ and $43 \% \mathrm{Ru}$ alloys exhibit lower recovered strains. An explanation may lie in the alloy composition: increasing disorder with deviation from equiatomic composition may decrease interface mobility. 


\begin{tabular}{|c|c|c|c|c|c|c|}
\hline & $\mathrm{Ru}_{50} \mathrm{Nb}_{50}$ & $\mathrm{Ru}_{50} \mathrm{Ta}_{50}$ & $\mathrm{Ru}_{45} \mathrm{Nb}_{55}$ & $\mathrm{Ru}_{45} \mathrm{Ta}_{55}$ & $\mathrm{Ru}_{43} \mathrm{Nb}_{57}$ & $\mathrm{Ru}_{43} \mathrm{Ta}_{57}$ \\
\hline $\mathrm{s}_{\text {th }}$ & 0.27 & 0.22 & 0.11 & 0.13 & 0.08 & 0.09 \\
\hline $\mathrm{s}_{\text {exp }}$ & 0.25 & 0.21 & 0.10 & 0.14 & 0.07 & 0.09 \\
\hline
\end{tabular}

Table 5. Theoretically and experimentally determined twinning shear amplitudes for the studied alloys. Note that theoretical values of monoclinic alloys use approximate calculated c/a reported in figure 1.

On the other hand, bending tests demonstrate a two way shape memory effect (TWSME) on the $\mathrm{Ru}_{45} \mathrm{Nb}_{55}[8$, 12]. Since the determination of recovered deformation is based on room temperature measurements, a TWSME may appear during cooling the sample, which can contribute to an apparent recovered deformation lower than in the $\mathrm{Ru}_{50} \mathrm{Nb}_{50}$ alloy.

It must be mentioned that this result includes, for the equiatomic alloys, the effect that is associated to the second transformation $\beta^{\prime} \rightarrow \beta^{\prime}$. A second series of experiments has been made for these alloys in order to investigate the shape memory effect related to the $\beta^{\prime} \rightarrow \beta^{\prime}$ ' transformation. Samples have been compressed in $\beta$ ' and reheated in $\beta$ '. Compression tests were performed at $\mathrm{M}_{\mathrm{p}}{ }^{\prime}{ }^{\prime}-55^{\circ} \mathrm{C}\left(690^{\circ} \mathrm{C}\right.$ for $\mathrm{Ru}_{50} \mathrm{Nb}_{50}$ and $730^{\circ} \mathrm{C}$ for $\left.\mathrm{Ru}_{50} \mathrm{Ta}_{50}\right)$ and followed by a heat treatment in the middle of the $\beta^{\prime}$ phase field $\left(850^{\circ} \mathrm{C}\right.$ for $\mathrm{Ru}_{50} \mathrm{Nb}_{50}$ and $900^{\circ} \mathrm{C}$ for $\left.\mathrm{Ru}_{50} \mathrm{Ta}_{50}\right)$, which gives the deformation that is recovered during the $\beta$ " $\rightarrow \beta$ ' transformation.

The following expression was used for the determination of residual and recovered deformations for the SME related to the $\beta$ ', $\rightarrow \beta$ ' transformation:

$$
\varepsilon_{\text {rec } \beta^{\prime}}=\frac{L_{T T \beta^{\prime}}-L}{L_{0}}
$$

$L_{T T \square}$, is the length of the specimen after the heat treatment in the $\beta$ ' phase.

Figure 8 shows the evolution of the recovered strain with the compression strain. The recovered strain is much lower than for the first series of experiments, which indicates that the most important part of the shape memory effect is due to the transformation $\beta \rightarrow \beta$ '. The recovered strain in $\mathrm{Ru}_{50} \mathrm{Ta}_{50}$ is higher than for $\mathrm{Ru}_{50} \mathrm{Nb}_{50}$ for the $\beta$ ' $\rightarrow \beta$ ' transformation.

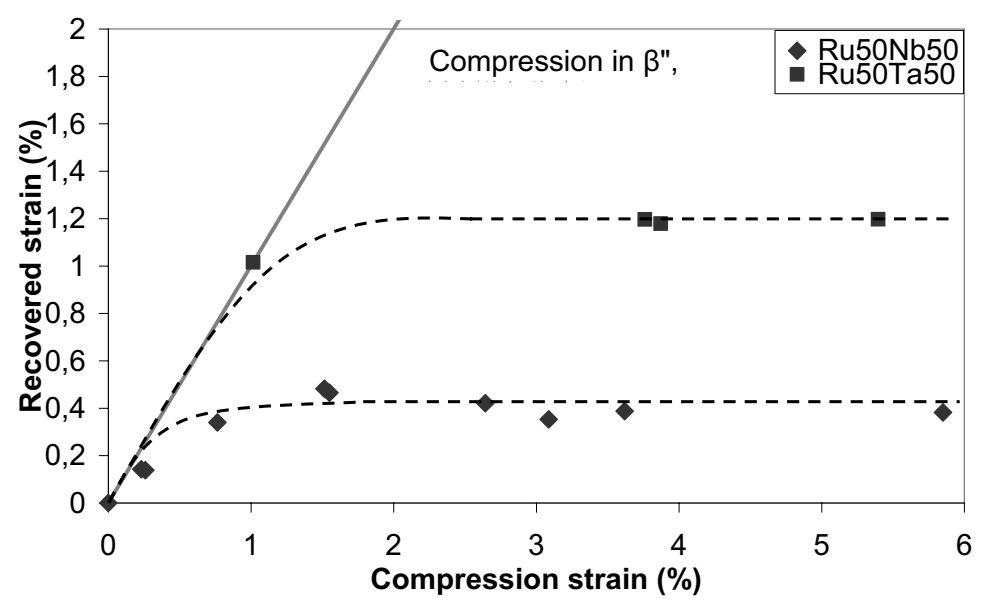

Fig. 8 Comparison between $\mathrm{Ru}_{50} \mathrm{Ta}_{50}$ and $\mathrm{Ru}_{50} \mathrm{Nb}_{50}$ for a compression in $\beta$ ', and a reheating in $\beta$ '

The lower recovery associated to the $\beta " \rightarrow \beta$ ' transformation may be explained as follows. As discussed in $\S 3.2$, a single orientation variant of $\beta$ ' gives rise to a single orientation variant of $\beta$ ''. Under the stress, the rearrangement of $\beta$ " variants proceeds mainly by twinning on (310) $\beta$ ", planes which correspond to $(101)_{\beta}$, planes. During the $\beta$ " $\rightarrow \beta$ ' reverse transformation, the variant reorganisation is kept thanks to the one-to-one orientation variant $\beta$ ' $/ \beta$ ' transformation. Finally, the twinning modified in the $\beta$ ' ' phase during straining disappears mainly during the $\beta^{\prime} \rightarrow \beta$ transformation, to which corresponds a higher shape memory effect.

\section{Conclusion}

The evolution of the microstructure and shape memory behaviour with composition has been investigated on binary high temperature shape memory alloys of the RuNb and RuTa systems. Following results have been found: 
- As expected from the phase diagrams, transformation temperatures decrease with lower Ru content. Transformation temperature $\left(\mathrm{M}_{\mathrm{S}}\right)$ for the $\beta \rightarrow \beta$ ' transformation varies from $887^{\circ} \mathrm{C}$ to $327^{\circ} \mathrm{C}$ and form $1038^{\circ} \mathrm{C}$ to $366^{\circ} \mathrm{C}$ from 50 at. $\%$ to $43 \mathrm{at} \%$ of $\mathrm{Ru}$ for the $\mathrm{RuNb}$ and the RuTa system, respectively.

- The same (011) compound twinning system has been found for all of the four tetragonal alloys. For both monoclinic alloys, it can be shown that observed $(310)_{\beta}$, twin planes correspond to (101) $)_{\beta}$, planes: the twinning system does not seem to be affected by the $\beta$ " ' $\rightarrow \beta$ ' transformation.

- X-ray and TEM diffraction patterns reveal that the c/a ratio of the tetragonal structure is affected by the composition, decreasing with $\mathrm{Ru}$ content for both systems. This may affect microstructural features, such as size and organisation of martensite variants.

- The recovery is mainly related to the $\beta^{\prime} \rightarrow \beta$ transformation, even if straining has been performed in the $\beta$ " monoclinic phase field

- Quantitative investigation of the shape memory behaviour of these alloys through compression tests reveals that the maximum shape recovery related to the $\beta \rightarrow \beta$ ' decreases from about $3 \%$ for equiatomic composition to less than $0.3 \%$ for alloys containing 43 at. $\%$ of Ru. This evolution of shape memory behaviour with composition may be explained by:

- $\quad$ A decrease of the twinning shear, in relation with evolution of the c/a ratio

- An easier variant interface mobility for the equiatomic composition,

- An easier variant interface mobility at high temperatures,

- A two way shape memory effect, such as observed in the $\mathrm{Ru}_{45} \mathrm{Nb}_{55}$ alloy, leading to an "apparent" shape recovery which is lower than in reality.

- The lower shape recovery during the $\beta$ " $\rightarrow \beta$ ' transformation $(0.4 \%$ and $1.5 \%$ for RuNb and RuTa system, respectively) may be related to a single orientation variant transformation.

\section{Acknowledgements}

J. van Humbeeck (KU Leuven) is gratefully acknowledged for DSC measurements. The authors are also grateful to C. Sanchez and A. Rafray for their help in experiments.

\section{References}

[1] K. Wu, J.L. Ma, A review of high-temperature shape memory alloys, Proceedings of the International Conference on Shape Memory and Superelastic Technologies, SMST-2000, Pacific Grove, CA, USA, 30 April-5 May 2000, SMST Publication, 2000, 153-161

[2] K. Otsuka and X. Ren, Recent developments in the research of shape memory alloys, Intermetallics, 7 (1999), 511-528

[3] N.V. Kataeva, S.V. Kosityn and A.I. Valiullin, Formation of $\mathrm{Ni}_{2} \mathrm{Al}$ and $\mathrm{Ni}_{3} \mathrm{Al}$ superstructures and reversibility of martensitic transformation in NiAl-Based B-alloys, Mat. Sci. Eng. A, 438-440 (2006), 312-314.

[4] R.W. Fonda, H.N. Jones and R.A. Vandermeer, The shape memory effect in equiatomic TaRu and $N b R u$ alloys , Scripta Mat., 39(8) (1998), 1031-1037

[5] R.W. Fonda, H.N. Jones, Microstructure, crystallography and shape memory effect in equiatomic NbRu, Mat. Sci. Eng. A, 273-275 (1999) 275-279

[6] X. Gao et al., Phase transformation behaviour and microstructure observation of Nb-Ru high temperature shape memory alloy, Acta Metallurgica Sinica (english letters), 16(5) (2003) 401-406

[7] B. K. Das and D.S. Lieberman, Displacive transformations in near-equiatomic niobium-ruthenium alloys I. Morphology and crystallography, Acta metallurgica., 23 (1975) 579-585

[8] K. Chastaing et al., High-temperature shape memory alloys based on the RuNb system, Mat. Sci. Eng. A, 481-482 (2008), 702-706

[9] X. Gao et al., Microstructure, compression property and shape memory effect of equiatomic TaRu high temperature shape memory alloy, Journal of Materials Science and Technology, 20(1) (2004), 97-99

[10] A. Denquin, K. Chastaing, P. Vermaut, D. Caillard, J. Van Humbeek, R. Portier, Shape recovery in RuNbbased high temperature shape memory alloys, Proceedings of the ICOMAT 2008 conference, Santa Fe, NM, USA, 28 June-4 July 2008, TMS publication

[11] K. Chastaing, P. Vermaut, A. Denquin, D. Caillard and R. Portier, TEM study of the martensitic transformations in RuNb alloys, presented at the ICOMAT 2008 conference, Santa Fe, NM, USA, 28 June-4 July 2008

[12] K. Chastaing, Ph. D Thesis, Study of Ru-based shape memory alloys for high temperature applications, University Pierre et Marie Curie, September 2007

[13] R.W. Fonda, R.A. Vandermeer, Crystallography and microstructure of TaRu, Philosophical Magazine A, 1997, Vol. 76, $\mathrm{N}^{\circ} 1,119-133$. 